\title{
Decision Making using Fuzzy PROMETHEE for Reverse Supply Chain Management Outsourcing
}

\author{
K. Koppiahraj, S. Bathrinath, S. Saravanasankar
}

\begin{abstract}
The rising awareness about environmental issues and the need to outrank the competitors necessitates reverse supply chain management. By implementing reverse supply chain process, the industries are able to recapture the products value and can minimize the production cost. The implementation of reverse supply chain management requires huge investment and upgraded technology. Hence most of the manufacturing sectors are outsourcing reverse supply chain management. When it comes to outsourcing, selection of appropriate supplier becomes a problem for industries. In this study, fuzzy Preference Ranking Organization Method for Enrichment Evaluation (fuzzy PROMETHEE) methodology is applied to select the best reverse supply chain management from five alternatives by four decision makers considering ten factors.
\end{abstract}

Keywords: Environmental issues, Fuzzy PROMETHEE, Outsourcing, Reverse supply chain process.

\section{INTRODUCTION}

$\mathrm{I}$ In recent years, outsourcing has become a common phenomenon observed in many manufacturing firms. In general, outsourcing is defined as the process of purchasing service or materials that are already provided by some external agencies. Companies prefer outsourcing for many reasons like effective procurement service, technology feasibility, cost optimization, flexibility and reducing number of employees. Outsourcing is commonly witnessed in industries like healthcare, accounting, IT sectors, manufacturing sectors and R\&Ds. A study states that Apple, Nike, IBM, Cisco and Wal-Mart are the most outsourcing companies in the world. A study carried by Chen et al. [1] on outsourcing in IT sectors indicates that most of the IT sectors are outsourcing for cost reduction and to focus more on internal resources. Most of the manufacturing industries are adopting reverse supply chain management as a step to curb production cost while emphasizing on environmental concern. Further, to combat the menace of End of Life (EOL) product and for effective waste management, reverse logistics (RL) is mandatory. As stated by Sarkis et al. [2], RL is defined as the process of co-coordinating activities such as process planning, effective cost management, inventory control from post-consumption to pre-consumption for proper disposal or recapturing value. Factors such as poor commitment from top management, lack of technology advancement and capital constraints are identified as potential

Revised Manuscript Received on December 05, 2019.

* Correspondence Author

K.Koppiahraj, Department of mechancical engineering, Kalasalingam Academy of research and education, Krishnankoil-626126, India. Email: koppiahraj1993@gmail.com

S.Bathrinath*, Department of mechancical engineering, Kalasalingam Academy of research and education, Krishnankoil-626126, India. Email: bathri@gmail.com

S.Saravanasankar, Department of mechancical engineering, Kalasalingam Academy of research and education, Krishnankoil-626126, India. Email: ssaravanasankar@klu.ac.in barrier in implementing environment oriented reverse logistics practice. Because of the above mentioned drawbacks, industries are unable to implement and control RL which leads to outsourcing. González-Torre et al. [3] evaluated the factors that are identified as barrier in implementing reverse logistics practice of an automotive sectors. As various factors influence the implementation and evaluation of RL, multi-criteria decision making (MCDM) methods are used. To overcome the vagueness and ambiguity while making decisions, fuzzy systems are incorporated with MCDM methods.

In this paper, fuzzy PROMETHEE method is used to select the best service provider in reverse supply chain for a leather shoe manufacturing industry.

\section{RELEVANT LITERATURES}

In this section, literatures relevant to reverse supply chain management, fuzzy MCDM methods are discussed. The necessity of reverse supply chain management is increasing tremendously as the result of better environmental awareness by both the industries and customers. In industries point of view, by implementing RL it is possible to bring down the production cost while increasing its social stature. In customers point of view, the discarded waste products are converted into useful products which mitigate landfills. Hence, implementing RL is beneficial for both manufactures and customers. Study carried by Alonso [4] and Beaumont and Sohal [5] evaluated the necessity of outsourcing in European Union and Australia. The study indicates that outsourcing generates more employment opportunities which will encounter unemployment and their study supported outsourcing. Spithoven and Teirlinck [6] investigated the reasons for outsourcing in research and development (R\&D) and indicated lack of in-house technological feasibility and internal resources as the prime factors for $R \& D$ outsourcing. Reverse Logistics (RL) have been an area of interest for many academicians and industrial researchers because of its increasing awareness. For a note, factors affecting implementation of RL in china [7], RL in computer industries [8], benchmarking RL process [9], RL barriers [10] are few examples. Sasikumar and Kannan [11] analyzed various difficulties in implementing RL practice and suggested some techniques to overcome the issues. Among various MCDM methods, PROMETHEE method is used specifically for outranking purpose. For outranking, PROMETHEE method in fuzzy context is generally preferred $[12,13]$.

\section{PROBLEM DESCRIPTION}

After reviewing earlier literatures and discussions with industrial managers, the following prevalent problems in reverse supply chain management are identified and listed below:

- Most of the manufacturing firms were of the view that implementation of reverse supply chain process is costly.

- Insufficient knowledge about the advantages of RL implementation. 


\section{Decision Making using Fuzzy PROMETHEE for Reverse Supply Chain Management Outsourcing}

- Non-availability of advanced technology in handling waste materials without having adverse impact on environment.

\section{EVALUATION METHODOLOGY}

Preference Ranking Organization Method for Enrichment Evaluations (PROMETHEE) methodology in fuzzy context is used for selecting the best reverse logistics network. The evaluation methodology is a combination PROMETHEE developed by [14] and fuzzy logics by [15]. The following are the steps involved in fuzzy PROMETHEE.

Step 1: Establish criteria, decision makers and alternatives. Let there be $i$ criteria, $j$ alternatives and $n$ decision makers.

Step 2: Define linguistics values and respective triangular fuzzy number. In this study, a five-scale linguistics variable with corresponding triangular fuzzy number is used to rate the criteria and prioritize the alternatives. Table 1 displays the five-scale linguistics variable and their corresponding fuzzy number.

Step 3: Aggregate the ratings provided by Decision makers. Using equation (1), the average priority weight of criteria is calculated.

$$
\tilde{w}_{i}=\frac{1}{n}\left[\sum_{e=1}^{n} \tilde{w_{i}^{e}}\right]=\frac{1}{n}\left[\tilde{w_{i}^{1}}+\tilde{w_{i}^{2}}+\ldots . .+\tilde{w}_{i}^{n}\right]
$$

The alternative preference by decision makers with respect to criteria is calculated using equation (2).

$$
\tilde{x_{i j}}=\frac{1}{n}\left[\sum_{e=1}^{n} \tilde{x_{i j}^{e}}\right]=\frac{1}{n}\left[\tilde{x_{i j}^{1}}+\tilde{x_{i j}^{2}}+\ldots .+\tilde{x_{i j}^{n}}\right]
$$

Step 4: Develop a fuzzy decision matrix and calculate average fuzzy weight.

$$
\begin{aligned}
& C_{1} C_{2} \Lambda \quad C_{i}
\end{aligned}
$$

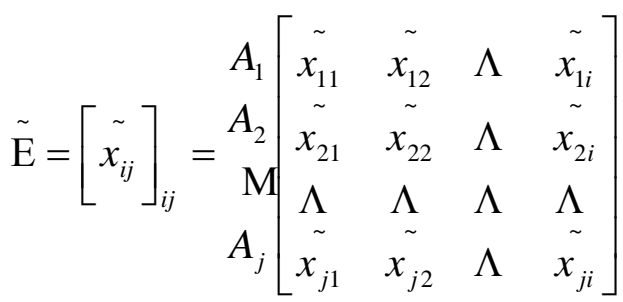

$x_{i j}$ - value of alternative $A_{i}$ with respect to criteria $C_{j}$

$$
\tilde{W}=\left[\tilde{w}_{1}, \tilde{w}_{2}, \ldots . ., \tilde{w}_{k}\right] j=1,2, \ldots, k
$$

$w_{j}-$ priority weight of criteria $i$

Step 5: Establish fuzzy preference function. Consider $A$ as a set of alternatives with $a$ and $b$. the preference function $\tilde{P}_{j}(a, b)$ can be defined as shown below.

$$
\tilde{P_{j}}(a, b)=\left\{\begin{array}{c}
0, \tilde{x}_{a j} \leq \tilde{x}_{b j} \\
\tilde{\sim}_{a j}, \tilde{x}_{b j}, \underset{x_{a j}}{\sim}>\tilde{x}_{b j}
\end{array}\right.
$$

Where $\tilde{P}_{j}(a, b)$ indicates the outranking intensity of $a$ over $b$.

The outranking relationship of alternatives based on pairwise comparison is defined as follow.

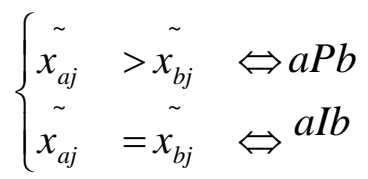

Step 6: Express multi-criteria preference index to rate outranking relations. Multi-criteria preference index $(\tilde{\pi}(a, b))$ can be expressed as shown below.

$$
\begin{aligned}
& \tilde{\pi}(a, b)=\frac{1}{k} \sum_{j=1}^{k} \tilde{P}_{j}(a, b) \\
& \tilde{\pi}(a, b)=\frac{\sum_{j=1}^{k}\left[\tilde{w}_{j} \tilde{P}_{j}(a, b)\right]}{\sum_{j=1}^{k} \tilde{w}_{j}}
\end{aligned}
$$

Step 7: Calculate the preorder flow of alternatives

Fuzzy PROMETHEE I: When the comparison of alternatives is not possible, the following relation is used.

$$
\text { Outgoing flow } \tilde{\phi^{+}}(a)=\sum_{y \neq a} \tilde{\pi}(a, y), \forall a, y \in A
$$

where $\tilde{\phi^{+}}(a)$ - total preference that $a$ is greater than other alternatives.

$$
\text { Incoming flow } \tilde{\phi^{-}}(a)=\sum_{y \neq a} \tilde{\pi}(a, y), \forall a, y \in A
$$

where $\phi^{-}(a)$ - total preference that other alternatives are greater than $a$. The values obtained using equation (9) and (10) is defuzzified.

Fuzzy PROMETHEE II: Compare and rank the alternatives. Depending on the net flow, all the alternatives are ranked. The net flow $(\phi(a))$ is defined as

$$
\phi(a)=\phi^{+}(a)-\phi^{-}(a), \forall \alpha \in A
$$

Alternative $a$ is better when $\phi(a)$ is larger.

Depending on incoming and outgoing flow, from PROMETHEE I, only partial preorder is obtained. In PROMETHEE II, depending on net flow, complete alternative ranking is obtained.

Step 8: Draw the outranking graph to rate the ranking of each alternatives.

\section{AN APPLICATION}

The case company considered for this work is a leather shoe manufacturing firm located in southern India. This manufacturing firm is interested in implementing reverse supply chain as a part of corporate social responsibility (CSR). As a new customer to reverse supply chain, the manufacturing firm is planning to outsource the reverse supply chain management. For selecting the best supplier in reverse supply chain management, fuzzy PROMETHEE methodology is adopted. In this study, five alternatives $\left(A_{1}, A_{2}, A_{3}\right.$, $\left.A_{4}, A_{5}\right)$ are chosen and are to evaluated by four decision makers $\left(D_{1}\right.$, $\left.\mathrm{D}_{2}, \mathrm{D}_{3}, \mathrm{D}_{4}\right)$. The evaluation of the alternatives by decision makers are based on the following factors: Environmental awareness $\left(\mathrm{F}_{1}\right)$, Effective Disposal system $\left(\mathrm{F}_{2}\right)$, Quality of returned product $\left(\mathrm{F}_{3}\right)$, Cost $\left(\mathrm{F}_{4}\right)$, Delivery $\left(\mathrm{F}_{5}\right)$, Technological Advancement $\left(\mathrm{F}_{6}\right)$, Co-ordination of activities $\left(\mathrm{F}_{7}\right)$, Handling capacity $\left(\mathrm{F}_{8}\right)$, Experience $\left(\mathrm{F}_{9}\right)$, Reliability $\left(\mathrm{F}_{10}\right)$. Next, using the five-scale linguistics variables (Table 1), the factors considered for selecting the alternatives are evaluated by decision makers. Table 2 displays the decision makers evaluation of factors and aggregated fuzzy weight of factors. Using equation (1), the fuzzy weight of each factor is calculated as shown below:

$\tilde{W}_{1}=\frac{1}{4}[V H+H+V H+V H]$ 
$=\frac{1}{4}(2.75,3.75,4.00)=(0.6875,0.9375,1.00)$

Normalized fuzzy evaluation of alternatives by decision makers and weighted normalized fuzzy matrix are shown in Table 3 and Table 4. Using equation (5), the fuzzy preference function in term of distance is calculated and shown on Table 5. Using the value of fuzzy preference function and criteria weight, fuzzy preference index are calculated and shown in Table 6. Fuzzy flows are calculated using equations (9) and (10) and shown in Table 7. The obtained fuzzy incoming and outgoing flows are defuzzified. After defuzzification, crisp incoming and outgoing flows are obtained and the results are shown in Table 8. The obtained net flows are $\phi\left(A_{1}\right)=0.0866, \phi\left(A_{2}\right)=0.0108, \phi\left(A_{3}\right)=-0.0583$, The $\phi\left(A_{4}\right)=-0.11744, \phi\left(A_{5}\right)=0.125$.

complete preorder ranking are $A_{5} P^{I I} A_{1} A_{1} P^{I I} A_{2}, A_{2} P^{I I} A_{3}, A_{3} P^{I I} A_{4}$. Based on this result, the valued outranking graph is shown in Fig.1

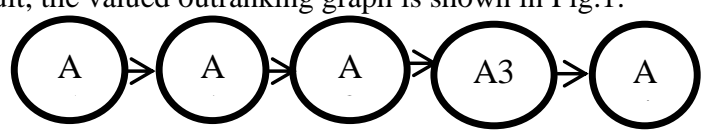

Fig.1. Complete Ranking of Alternatives

\section{RESULT AND DISCUSSIONS}

From the average priority weight of factors (Table 2), it could be understood that while selecting third party reverse logistics provider, environmental compliance of the service provider must be given top priority. Other factors such as Effective disposal system $\left(\mathrm{F}_{2}\right)$, cost $\left(\mathrm{F}_{4}\right)$ and Handling capacity $\left(\mathrm{F}_{8}\right)$ must be noticed while selecting service provider. Based on the results as shown in fig. 1, the alternative $\mathrm{A}_{5}$ provides best reverse supply chain management. It should be noticed that the alternative $\mathrm{A}_{5}$ outranks all other alternatives in vital factors concerning environmentally assisted reverse logistic provider.

\section{CONCLUSION}

The case company visited for this study is interested in adopting environment friendly reverse supply chain management. However, due to low capital investment and non-availability of advanced technology, the company decides to outsource reverse supply chain management. To assist the company in selecting best service provider, a study was carried with the assistance of decision makers. In this work, fuzzy PROMETHEE method is applied to identify the ideal service provider in reverse supply chain management for leather shoe manufacturing industry. From the study, it is suggested that fuzzy PROMETHEE method is simple to use and will provide solutions for real time problem in short span. The obtained results of ranking will assist the decision makers or industry in selecting best service provider of reverse supply chain management.

\section{REFERENCES}

1. Y. H. Chen, T. C. Wang and C. Y. Wu, "Strategicic decisions using the fuzzy PROMETHEE for IS outsourcing," Expert Systems with Applications, Vol. 38(10), 2011, 13216-13222.

2. J. Sarkis, M. M. Helms and A. A. Hervani, "Reverse logistics and social sustainability," Corporate Social Responsibility and Environmental Management, Vol. 17(6), 2010, 337-354.

3. P. González-Torre, M. Alvarez, J. Sarkis and B. Adenso-Díaz, Barriers to the implementation of environmentally oriented reverse logistics: evidence from the automotive industry sector. British Journal of Management, Vol. 21(4), 2010, 889-904.

4. J. M. Alonso, J. Clifton and D. Díaz-Fuentes, "The impact of government outsourcing on public spending: Evidence from
European Union countries,” Journal of Policy Modeling, Vol. 39(2), 2017, 333-348.

5. N. Beaumont and A. Sohal, "Outsourcing in Australia," International Journal of Operations \& Production Management, Vol. 24(7), 2004, 688-700.

6. A. Spithoven and P. Teirlinck, "Internal capabilities, network resources and appropriation mechanisms as determinants of R\&D outsourcing," Research policy, Vol. 44(3), 2015, 711-725.

7. N. Subramanian, A. Gunasekaran, M. Abdulrahman and C. Liu, "Factors for implementing end-of-life product reverse logistics in the Chinese manufacturing sector," International Journal of Sustainable Development \& World Ecology, Vol. 21(3), 2014, 235-245.

8. S. M. Ali, A. Arafin, M. A. Moktadir, T. Rahman and N. Zahan, "Barriers to reverse logistics in the computer supply chain using interpretive structural model," Global journal of flexible systems management, Vol. 19(1), 2018, 53-68.

9. S. K. Sharma, S. S. Mahapatra and M. B. Parappagoudar, "Benchmarking of product recovery alternatives in reverse logistics," Benchmarking: An International Journal, Vol. 23(2), 2016, 406-424.

10. M. Tavana, M. Zareinejad, D. Di Caprio, and M. A. Kaviani, "An integrated intuitionistic fuzzy AHP and SWOT method for outsourcing reverse logistics," Applied Soft Computing, Vol. 40, 2016, 544-557.

11. P. Sasikumar and G. Kannan, "Issues in reverse supply chain, part III: classification and simple analysis," International Journal of Sustainable Engineering, Vol. 2(1), 2009, 2-27.

12. T. Briggs and P. L.Kunsch and B. Mareschal "Nuclear waste management: an application of the multicriteria PROMETHEE methods," European Journal of Operational Research, Vol. 44(1), 1990, 1-10.

13. R. Dulmin and V. Mininno, "Supplier selection using a multi-criteria decision aid method," Journal of purchasing and supply management, Vol. 9(4), 2003, 177-187.

14. J. P. Brans, P. Vincke and B. Mareschal, "How to select and how to rank projects: The PROMETHEE method," European journal of operational research, Vol. 24(2), 1986, 228-238.

15. L. A. Zadeh, "Fuzzy sets," Information and control, Vol. 8(3), 1965 338-353.

\section{AUTHORS PROFILE}

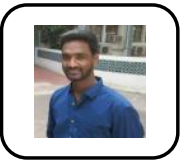

K.Koppiahraj obtained his B.E (MECH) in 2014 from the Erode sengunthar engineering college, Erode, Tamilnadu, India. $\mathrm{He}$ completed his M.Tech (CAD/CAM) in 2016 at the B.S.Abdur Rahman Crescent institute of science and technology, Chennai, Tamilnadu, India. Currently, he is a Research Scholar in the Department of Mechanical Engineering, Kalasalingam Academy of Research and Education, Krishnankoil, Tamilnadu, India. His research interests include multi-criteria decision making and application of fuzzy set theory in real life decision problems. He is currently pursuing PHD in the area of analyzing Day-today challegnes in leather industries using MCDM techniques.

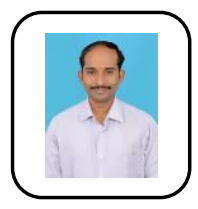

Dr.S.Bathrinath is an Associate Professor in the Department of Mechanical Engineering, Kalasalingam Academy of Research and Education, Krishnankoil, Tamilnadu, India. His current area of research includes multi-criteria decision making, scheduling \& optimization, soft computing and Artificial intelligence. He has published a number of papers in journal of national/international repute and presented a number of papers in various conferences/symposia in India and abroad. He is presently guiding a number of master/doctoral research scholars. Dr.S.Bathrinath is the corresponding author and can be contacted at: bathri@gmail.com

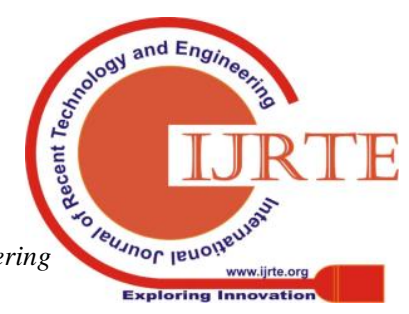


Decision Making using Fuzzy PROMETHEE for Reverse Supply Chain Management Outsourcing

Dr.S.Saravanasankar is a Senior Professor in the Department of Mechanical Engineering, Kalasalingam Academy of Research and Education, Krishnankoil, Tamilnadu, India. He has more than 20 years of experience in teaching and research. His current area of research includes scheduling, optimization and multi-criteria decision making. He has published more than 40 research articles in journals of national and international repute.

Table- I: Linguistics variable with respective fuzzy numbers

\begin{tabular}{l}
$\begin{array}{c}\text { Linguistic Variable } \\
\text { for Criteria } \\
\text { weighting }\end{array}$ \\
\hline
\end{tabular}

\begin{tabular}{ccc}
\hline Very High (VH) & $(0.75,1.00,1.00)$ & Best (B) \\
High (H) & $(0.50,0.75,1.00)$ & Good (G) \\
Medium (M) & $(0.25,0.50,0.75)$ & Fair (F) \\
Low (L) & $(0.00,0.25,0.50)$ & Poor (P) \\
Very Low (VL) & $(0.00,0.00,0.25)$ & Worst (W) \\
\hline
\end{tabular}

Table- II: Weight of each factor

\begin{tabular}{cccccc}
\hline & $\mathrm{D}_{1}$ & $\mathrm{D}_{2}$ & $\mathrm{D}_{3}$ & $\mathrm{D}_{4}$ & Fuzzy Weight \\
\hline $\mathrm{F}_{1}$ & $\mathrm{VH}$ & $\mathrm{H}$ & $\mathrm{VH}$ & $\mathrm{VH}$ & $(0.6875,0.9375,1.00)$ \\
$\mathrm{F}_{2}$ & $\mathrm{VH}$ & $\mathrm{VH}$ & $\mathrm{VH}$ & $\mathrm{VH}$ & $(0.75,1.00,1.00)$ \\
$\mathrm{F}_{3}$ & $\mathrm{VH}$ & $\mathrm{H}$ & $\mathrm{H}$ & $\mathrm{H}$ & $(0.5625,0.8125,1.00)$ \\
$\mathrm{F}_{4}$ & $\mathrm{VH}$ & $\mathrm{VH}$ & $\mathrm{VH}$ & $\mathrm{VH}$ & $(0.75,1.00,1.00)$ \\
$\mathrm{F}_{5}$ & $\mathrm{VH}$ & $\mathrm{H}$ & $\mathrm{H}$ & $\mathrm{M}$ & $(0.50,0.75,0.9375)$ \\
$\mathrm{F}_{6}$ & $\mathrm{VH}$ & $\mathrm{VH}$ & $\mathrm{VH}$ & $\mathrm{VH}$ & $(0.75,1.00,1.00)$ \\
$\mathrm{F}_{7}$ & $\mathrm{M}$ & $\mathrm{H}$ & $\mathrm{H}$ & $\mathrm{M}$ & $(0.50,0.625,0.875)$ \\
$\mathrm{F}_{8}$ & $\mathrm{H}$ & $\mathrm{M}$ & $\mathrm{L}$ & $\mathrm{VH}$ & $(0.375,0.625,0.8125)$ \\
$\mathrm{F}_{9}$ & $\mathrm{H}$ & $\mathrm{H}$ & $\mathrm{H}$ & $\mathrm{H}$ & $(0.50,0.75,1.00)$ \\
$\mathrm{F}_{10}$ & $\mathrm{VH}$ & $\mathrm{VH}$ & $\mathrm{VH}$ & $\mathrm{VH}$ & $(0.75,1.00,1.00)$ \\
\hline & & & & & \\
\hline
\end{tabular}

Table- III. Normalized fuzzy decision matrix

\begin{tabular}{lccccc}
\hline & $\mathrm{A}_{1}$ & $\mathrm{~A}_{2}$ & $\mathrm{~A}_{3}$ & $\mathrm{~A}_{4}$ & $\mathrm{~A}_{5}$ \\
\hline $\mathrm{F}_{1}$ & $(0.75,1.00,1.00)$ & $(0.75,1.00,1.00)$ & $(0.50,0.75,1.00)$ & $(0.50,0.75,1.00)$ & $(0.50,0.75,1.00)$ \\
$\mathrm{F}_{2}$ & $(0.75,1.00,1.00)$ & $(0.75,1.00,1.00)$ & $(0.75,1.00,1.00)$ & $(0.75,1.00,1.00)$ & $(0.75,1.00,1.00)$ \\
$\mathrm{F}_{3}$ & $(0.50,0.75,1.00)$ & $(0.50,0.75,1.00)$ & $(0.50,0.75,1.00)$ & $(0.25,0.50,0.75)$ & $(0.50,0.75,1.00)$ \\
$\mathrm{F}_{4}$ & $(0.75,1.00,1.00)$ & $(0.75,1.00,1.00)$ & $(0.75,1.00,1.00)$ & $(0.75,1.00,1.00)$ & $(0.75,1.00,1.00)$ \\
$\mathrm{F}_{5}$ & $(0.50,0.75,1.00)$ & $(0.50,0.75,1.00)$ & $(0.50,0.75,1.00)$ & $(0.50,0.75,1.00)$ & $(0.50,0.75,1.00)$ \\
$\mathrm{F}_{6}$ & $(0.50,0.75,1.00)$ & $(0.50,0.75,1.00)$ & $(0.75,1.00,1.00)$ & $(0.75,1.00,1.00)$ & $(0.75,1.00,1.00)$ \\
$\mathrm{F}_{7}$ & $(0.50,0.75,1.00)$ & $(0.50,0.75,1.00)$ & $(0.25,0.50,0.75)$ & $(0.25,0.50,0.75)$ & $(0.25,0.50,0.75)$ \\
$\mathrm{F}_{8}$ & $(0.25,0.50,0.75)$ & $(0.25,0.50,0.75)$ & $(0.25,0.50,0.75)$ & $(0.50,0.75,1.00)$ & $(0.75,1.00,1.00)$ \\
$\mathrm{F}_{9}$ & $(0.75,1.00,1.00)$ & $(0.75,1.00,1.00)$ & $(0.75,1.00,1.00)$ & $(0.75,1.00,1.00)$ & $(0.75,1.00,1.00)$ \\
$\mathrm{F}_{10}$ & $(0.75,1.00,1.00)$ & $(0.75,1.00,1.00)$ & $(0.75,1.00,1.00)$ & $(0.75,1.00,1.00)$ & $(0.75,1.00,1.00)$ \\
\hline
\end{tabular}

Table- IV: Weight normalized fuzzy matrix

\begin{tabular}{|c|c|c|c|c|c|}
\hline & $\mathrm{A}_{1}$ & $\mathrm{~A}_{2}$ & $\mathrm{~A}_{3}$ & $\mathrm{~A}_{4}$ & $\mathrm{~A}_{5}$ \\
\hline $\mathrm{F}_{1}$ & $(0.52,0.94,1.00)$ & $(0.52,1.00,1.00)$ & $(0.34,0.52,1.00)$ & $(0.34,0.52,1.00)$ & $(0.34,0.52,1.00)$ \\
\hline $\mathrm{F}_{2}$ & $(0.5625,1.00,1.00)$ & $(0.5625,1.00,1.00)$ & $(0.5625,1.00,1.00)$ & $(0.5625,1.00,1.00)$ & $(0.5625,1.00,1.00)$ \\
\hline $\mathrm{F}_{3}$ & $(0.28,0.61,1.00)$ & $(0.28,0.61,1.00)$ & $(0.28,0.61,1.00)$ & $(0.14,0.28,0.61)$ & $(0.28,0.61,1.00)$ \\
\hline $\mathrm{F}_{4}$ & $(0.5625,1.00,1.00)$ & $(0.5625,1.00,1.00)$ & $(0.5625,1.00,1.00)$ & $(0.5625,1.00,1.00)$ & $(0.5625,1.00,1.00)$ \\
\hline $\mathrm{F}_{5}$ & $(0.25,0.56,0.9375)$ & $(0.25,0.56,0.9375)$ & $(0.25,0.56,0.9375)$ & $(0.25,0.56,0.9375)$ & $(0.25,0.56,0.9375)$ \\
\hline $\mathrm{F}_{6}$ & $(0.38,0.75,1.00)$ & $(0.38,0.75,1.00)$ & $(0.56,1.00,1.00)$ & $(0.56,1.00,1.00)$ & $(0.56,1.00,1.00)$ \\
\hline $\mathrm{F}_{7}$ & $(0.25,0.47,0.875)$ & $(0.25,0.47,0.875)$ & $(0.125,0.31,0.66)$ & $(0.125,0.31,0.66)$ & $(0.125,0.31,0.66)$ \\
\hline $\mathrm{F}_{8}$ & $(0.9,0.31,0.61)$ & $(0.9,0.31,0.61)$ & $(0.9,0.31,0.61)$ & $(0.1875,0.47,0.8125)$ & $(0.28,0.625,0.8125)$ \\
\hline $\mathrm{F}_{9}$ & $(0.375,0.75,1.00)$ & $(0.375,0.75,1.00)$ & $(0.375,0.75,1.00)$ & $(0.375,0.75,1.00)$ & $(0.375,0.75,1.00)$ \\
\hline $\mathrm{F}_{10}$ & $(0.5625,1.00,1.00)$ & $(0.5625,1.00,1.00)$ & $(0.5625,1.00,1.00)$ & $(0.5625,1.00,1.00)$ & $(0.5625,1.00,1.00)$ \\
\hline
\end{tabular}

Table- V: Fuzzy Preference function by distance

\begin{tabular}{ccccccccccccc}
\hline & $\mathrm{F}_{1}$ & $\mathrm{~F}_{2}$ & $\mathrm{~F}_{3}$ & $\mathrm{~F}_{4}$ & $\mathrm{~F}_{5}$ & $\mathrm{~F}_{6}$ & $\mathrm{~F}_{7}$ & $\mathrm{~F}_{8}$ & $(0,0,0)$ & $(0,0,0)$ & $(0,0,0)$ & $(0,0,0)$ \\
\hline $\mathrm{P}(1,2)$ & $(0,0,0)$ & $(0,0,0)$ & $(0,0,0)$ & $(0,0,0)$ & $(0,0,0)$ & $(0,0,0)$ & $(0,0,0)$ & $(0,0)$ & $(0,0,0)$ & $(0,0)$ & $(0,0,0)$ & $(0,0)$ \\
$\mathrm{P}(1,3)$ & $(0.25,0.25,0)$ & $(0,0,0)$ & $(0,0,0)$ & $(0,0,0)$ & $(0,0,0)$ & $(0,0,0)$ & $(0.25,0.25,0.25)$ & $(0,0)$ \\
$\mathrm{P}(1,4)$ & $(0.25,0.25,0)$ & $(0,0,0)$ & $(0.25,0.25,0.25)$ & $(0,0,0)$ & $(0,0,0)$ & $(0,0,0)$ & $(0.25,0.25,0.25)$ & $(0,0,0)$ & $(0,0,0)$ & $(0,0,0)$ & $(0,0)$ \\
$\mathrm{P}(1,5)$ & $(0.25,0.25,0)$ & $(0,0,0)$ & $(0,0,0)$ & $(0,0,0)$ & $(0,0,0)$ & $(0,0,0)$ & $(0.25,0.25,0.25)$ & $(0,0,0)$ & $(0,0,0)$ & $(0,0,0)$ \\
\hline
\end{tabular}


International Journal of Recent Technology and Engineering (IJRTE) ISSN: 2277-3878, Volume-8 Issue-4S2, December 2019

\begin{tabular}{|c|c|c|c|c|c|c|c|c|c|c|}
\hline $\mathrm{P}(2,1)$ & $(0,0,0)$ & $(0,0,0)$ & $(0,0,0)$ & $(0,0,0)$ & $(0,0,0)$ & $(0,0,0)$ & $(0,0,0)$ & $(0,0,0)$ & $(0,0,0)$ & $(0,0,0)$ \\
\hline $\mathrm{P}(2,3)$ & $(0.25,0.25,0)$ & $(0,0,0)$ & $(0,0,0)$ & $(0,0,0)$ & $(0,0,0)$ & $(0,0,0)$ & $(0.25,0.25,0.25)$ & $(0,0,0)$ & $(0,0,0)$ & $(0,0,0)$ \\
\hline $\mathrm{P}(2,4)$ & $(0.25,0.25,0)$ & $(0,0,0)$ & $(0.25,0.25,0.25)$ & $(0,0,0)$ & $(0,0,0)$ & $(0,0,0)$ & $(0.25,0.25,0.25)$ & $(0,0,0)$ & $(0,0,0)$ & $(0,0,0)$ \\
\hline $\mathrm{P}(2,5)$ & $(0.25,0.25,0)$ & $(0,0,0)$ & $(0,0,0)$ & $(0,0,0)$ & $(0,0,0)$ & $(0,0,0)$ & $(0.25,0.25,0.25)$ & $(0,0,0)$ & $(0,0,0)$ & $(0,0,0)$ \\
\hline $\mathrm{P}(3,1)$ & $(0,0,0)$ & $(0,0,0)$ & $(0,0,0)$ & $(0,0,0)$ & $(0,0,0)$ & $(0.25,0.25,0)$ & $(0,0,0)$ & $(0,0,0)$ & $(0,0,0)$ & $(0,0,0)$ \\
\hline $\mathrm{P}(3,2)$ & $(0,0,0)$ & $(0,0,0)$ & $(0,0,0)$ & $(0,0,0)$ & $(0,0,0)$ & $(0.25,0.25,0)$ & $(0,0,0)$ & $(0,0,0)$ & $(0,0,0)$ & $(0,0,0)$ \\
\hline $\mathrm{P}(3,4)$ & $(0,0,0)$ & $(0,0,0)$ & $(0.25,0.25,0.25)$ & $(0,0,0)$ & $(0,0,0)$ & $(0,0,0)$ & $(0,0,0)$ & $(0,0,0)$ & $(0,0,0)$ & $(0,0,0)$ \\
\hline $\mathrm{P}(3,5)$ & $(0,0,0)$ & $(0,0,0)$ & $(0,0,0)$ & $(0,0,0)$ & $(0,0,0)$ & $(0,0,0)$ & $(0,0,0)$ & $(0,0,0)$ & $(0,0,0)$ & $(0,0,0)$ \\
\hline $\mathrm{P}(4,1)$ & $(0,0,0)$ & $(0,0,0)$ & $(0,0,0)$ & $(0,0,0)$ & $(0,0,0)$ & $(0.25,0.25,0)$ & $(0,0,0)$ & $(0.25,0.25,0.25)$ & $(0,0,0)$ & $(0,0,0)$ \\
\hline $\mathrm{P}(4,2)$ & $(0,0,0)$ & $(0,0,0)$ & $(0,0,0)$ & $(0,0,0)$ & $(0,0,0)$ & $(0.25,0.25,0)$ & $(0,0,0)$ & $(0.25,0.25,0.25)$ & $(0,0,0)$ & $(0,0,0)$ \\
\hline $\mathrm{P}(4,3)$ & $(0,0,0)$ & $(0,0,0)$ & $(0,0,0)$ & $(0,0,0)$ & $(0,0,0)$ & $(0,0,0)$ & $(0,0,0)$ & $(0.25,0.25,0.25)$ & $(0,0,0)$ & $(0,0,0)$ \\
\hline $\mathrm{P}(4,5)$ & $(0,0,0)$ & $(0,0,0)$ & $(0,0,0)$ & $(0,0,0)$ & $(0,0,0)$ & $(0,0,0)$ & $(0,0,0)$ & $(0,0,0)$ & $(0,0,0)$ & $(0,0,0)$ \\
\hline $\mathrm{P}(5,1)$ & $(0,0,0)$ & $(0,0,0)$ & $(0,0,0)$ & $(0,0,0)$ & $(0,0,0)$ & $(0.25,0.25,0)$ & $(0,0,0)$ & $(0.50,0.50,0.25)$ & $(0,0,0)$ & $(0,0,0)$ \\
\hline $\mathrm{P}(5,2)$ & $(0,0,0)$ & $(0,0,0)$ & $(0,0,0)$ & $(0,0,0)$ & $(0,0,0)$ & $(0.25,0.25,0)$ & $(0,0,0)$ & $(0.50,0.50,0.25)$ & $(0,0,0)$ & $(0,0,0)$ \\
\hline $\mathrm{P}(5,3)$ & $(0,0,0)$ & $(0,0,0)$ & $(0,0,0)$ & $(0,0,0)$ & $(0,0,0)$ & $(0,0,0)$ & $(0,0,0)$ & $(0.50,0.50,0.25)$ & $(0,0,0)$ & $(0,0,0)$ \\
\hline $\mathrm{P}(5,4)$ & $(0,0,0)$ & $(0,0,0)$ & $(0.25,0.25,0.25)$ & $(0,0,0)$ & $(0,0,0)$ & $(0,0,0)$ & $(0,0,0)$ & $(0.25,0.25,0)$ & $(0,0,0)$ & $(0,0,0)$ \\
\hline
\end{tabular}

Table- VI: Fuzzy Preference Index

\begin{tabular}{cccccc}
\hline & $\mathrm{A}_{1}$ & $\mathrm{~A}_{2}$ & $\mathrm{~A}_{3}$ & ${ }^{\prime} \mathrm{A}_{4}$ & $\mathrm{~A}_{5}$ \\
\hline $\mathrm{A}_{1}$ & - & $(0,0,0)$ & $(0.30,0.39,0.22)$ & $(0.43,0.60,0.47)$ & $(0.30,0.39,0.22)$ \\
$\mathrm{A}_{2}$ & $(0,0,0)$ & - & $(0,0,0)$ & $(0.43,0.60,0.47)$ & $(0.30,0.39,0.22)$ \\
$\mathrm{A}_{3}$ & $(0.18,0.25,0)$ & $(0.18,0.25,0)$ & - & $(0.13,0.21,0.25)$ & $(0,0,0)$ \\
$\mathrm{A}_{4}$ & $(0.27,0.41,0.20)$ & $(0.27,0.41,0.20)$ & $(0.09,0.16,0.20)$ & - & $(0,0,0)$ \\
$\mathrm{A}_{5}$ & $(0.36,0.41,0.20))$ & $(0.36,0.41,0.20)$ & $(0.18,0.16,0.20)$ & $(0.22,0.37,0.25)$ & - \\
\hline
\end{tabular}

Table- VII: Outgoing and Incoming flow of Alternatives

\begin{tabular}{ccc}
\hline & Fuzzy Incoming flow & Fuzzy Outgoing flow \\
\hline $\mathrm{A}_{1}$ & $(0.2025,0.2675,0.1)$ & $(0.2575,0.345,0.2275)$ \\
$\mathrm{A}_{2}$ & $(0.2025,0.2675,0.1)$ & $(0.1825,0.2475,0.1725)$ \\
$\mathrm{A}_{3}$ & $(0.1425,0.1775,0.155)$ & $(0.1225,0.1775,0)$ \\
$\mathrm{A}_{4}$ & $(0.3025,0.445,0.36)$ & $(0.36,0.245,0.15)$ \\
$\mathrm{A}_{5}$ & $(0.15,0.195,0.11)$ & $(0.28,0.3375,0.2125)$ \\
\hline
\end{tabular}

Table- VIII: Prioritization of each alternative

\begin{tabular}{ccccc}
\hline & Crisp Outgoing flow & Crisp Incoming flow & Net flow \\
\hline $\mathrm{A}_{1}$ & 0.2766 & 0.19 & 0.0866 & 2 \\
$\mathrm{~A}_{2}$ & 0.2008 & 0.19 & 0.0108 & 3 \\
$\mathrm{~A}_{3}$ & 0.1 & 0.1583 & -0.0583 & 4 \\
$\mathrm{~A}_{4}$ & 0.25166 & 0.3691 & -0.11744 \\
$\mathrm{~A}_{5}$ & 0.2766 & 0.1516 & 0.125 & 5 \\
\hline
\end{tabular}

